\title{
Alcohol consumption, cigarette smoking and the risk of subtypes of head-neck cancer: results from the Netherlands Cohort Study
}

\author{
Denise HE Maasland ${ }^{1 *}$, Piet A van den Brandt ${ }^{1}$, Bernd Kremer $^{2}$, R Alexandra (Sandra) Goldbohm \\ and Leo J Schouten ${ }^{\prime}$
}

\begin{abstract}
Background: Prospective data on alcohol consumption, cigarette smoking and risk of head-neck cancer (HNC) subtypes, i.e. oral cavity cancer (OCC), oro-/hypopharyngeal cancer (OHPC), and laryngeal cancer (LC), are limited. We investigated these associations within the second largest prospective study on this topic so far, the Netherlands Cohort Study.

Methods: 120,852 participants completed a questionnaire on diet and other cancer risk factors in 1986. After 17.3 years of follow-up, 395 HNC (110 OCC, 83 OHPC, and 199 LC) cases and 4288 subcohort members were available for case-cohort analysis using Cox proportional hazards models.

Results: For total HNC, the multivariable adjusted incidence rate ratio (RR) was 2.74 (95\% confidence interval (Cl) 1.85-4.06) for those drinking $\geq 30 \mathrm{~g}$ ethanol/day compared with abstainers; in subtypes, RRs were 6.39 for OCC, 3.52 for OHPC, and 1.54 for LC. Compared with never cigarette smokers, current cigarette smokers had a RR of 4.49 (95\% Cl 3.11-6.48) for HNC overall, and 2.11 for OCC, 8.53 for OHPC, and 8.07 for LC. A significant, positive, multiplicative interaction between categories of alcohol consumption and cigarette smoking was found for HNC overall (P interaction 0.03).

Conclusions: Alcohol consumption and cigarette smoking were independently associated with risk of HNC overall, with a positive, multiplicative interaction. The strength of these associations differed among HNC-subtypes: OCC was most strongly associated with alcohol consumption but most weakly with cigarette smoking, whereas LC was not statistically significantly associated with alcohol consumption.
\end{abstract}

Keywords: Alcohol consumption, Cigarette smoking, Cohort studies, Etiology, Head-neck cancer, Head-neck cancer subtypes

\section{Background}

Head and neck cancer (HNC) includes several malignancies that originate in the paranasal sinuses, nasal cavity, salivary glands, oral cavity, pharynx, and larynx [1]. HNC is the seventh most common type of cancer in the world and in the European Union; in Europe, HNC accounts for an estimated 130,000 new cases every year [2].

\footnotetext{
* Correspondence: denise.maasland@maastrichtuniversity.n 'Department of Epidemiology, GROW - School for Oncology \& Developmental Biology, Maastricht University, P.O. Box 616, Maastricht 6200 $M D$, The Netherlands
}

Full list of author information is available at the end of the article
Alcohol consumption and cigarette smoking are established risk factors for HNC originating from the oral cavity, pharynx, and larynx, and are likely to be differentially associated with risk of those HNC-subtypes [3-8]. However, the majority of conducted studies are case-control studies, a study design susceptible to misclassification with regard to exposure. Prospective cohort studies are less sensitive to this bias, but only six population-based cohort studies have reported on alcohol consumption, cigarette smoking and HNC-risk [9-15]. Of these studies, most had a small number of cases and were thereby hardly able to examine subtypes; HNC was often combined with other cancers into upper aerodigestive tract cancer [9,12-15]. In 
addition, the largest prospective study so far lacked information on smoking duration [10]. Finally, a greater than multiplicative joint effect between alcohol and tobacco consumption has been shown, but most evidence comes from case-control studies as well [9,12-14,16-18].

Therefore, we wanted to investigate these associations in HNC-subtypes within the large prospective Netherlands Cohort Study (NLCS). We focused on the most frequent HNC-subtypes: those located in the oral cavity, pharynx, and larynx, and hypothesized that 1) alcohol consumption and cigarette smoking are strongly, positively associated with HNC-risk, with multiplicative interaction, and that 2) these risks are different for oral cavity cancer (OCC), oro-/hypopharyngeal cancer (OHPC), and laryngeal cancer (LC).

\section{Methods}

\section{Design and study population}

The present study was conducted within the NLCS, which started in September 1986 with the inclusion of 120,852 participants, aged 55-69 years from 204 Dutch municipal population registries [19].

For data processing and analysis, the case-cohort design was used for reasons of efficiency [20]. Cases were derived from the total cohort, whereas the number of person-years at risk for the total cohort was estimated from a subcohort of 5000 persons, randomly sampled from the entire cohort at baseline.

Follow-up for cancer incidence was done by annual record linkage to the Netherlands Cancer Registry and the nationwide network and pathology registry [21]. The completeness of cancer follow-up is estimated to be $\geq 96 \%$
[22], and follow-up for vital status of the subcohort was nearly $100 \%$ complete after 17.3 years.

We excluded cohort members who reported to have prevalent cancer other than skin cancer at baseline, and cases and subcohort members with missing data on exposure or confounding variables. Only microscopically confirmed, first occurrences of squamous cell carcinomas - which include nearly all malignancies of the mouth, pharynx, and larynx $[1,3]$ - of the head and neck were included.

In total, 395 incident $\mathrm{HNC}$ cases and 4288 subcohort members were available for analysis (Figure 1). Of these cases, 110 were oral cavity cancer (ICD-O-3 C003-009, C020-C023, C030-C031, C039-C041, C048-C050, C060C062, C068-C069), 83 oro-/hypopharyngeal cancer (C019, C024, C051-C052, C090-C091, C098-C104, C108-C109, C129-C132, C138-C139); 3 oral cavity, pharynx unspecified, or overlapping (C028-C029, C058-C059, C140-C142, C148), and 199 laryngeal cancer (C320-C329) cases, classified as proposed by Hashibe et al. [23], according to the International Classification of Diseases for Oncology (ICD-O-3) [24].

The NLCS has been approved by the Medical Ethics Committee of Maastricht University (Maastricht, The Netherlands).

\section{Exposure information}

At baseline, all cohort members completed a selfadministered questionnaire, which included a 150-item food frequency questionnaire (FFQ) with detailed questions on alcohol consumption, smoking habits, and other cancer risk factors.

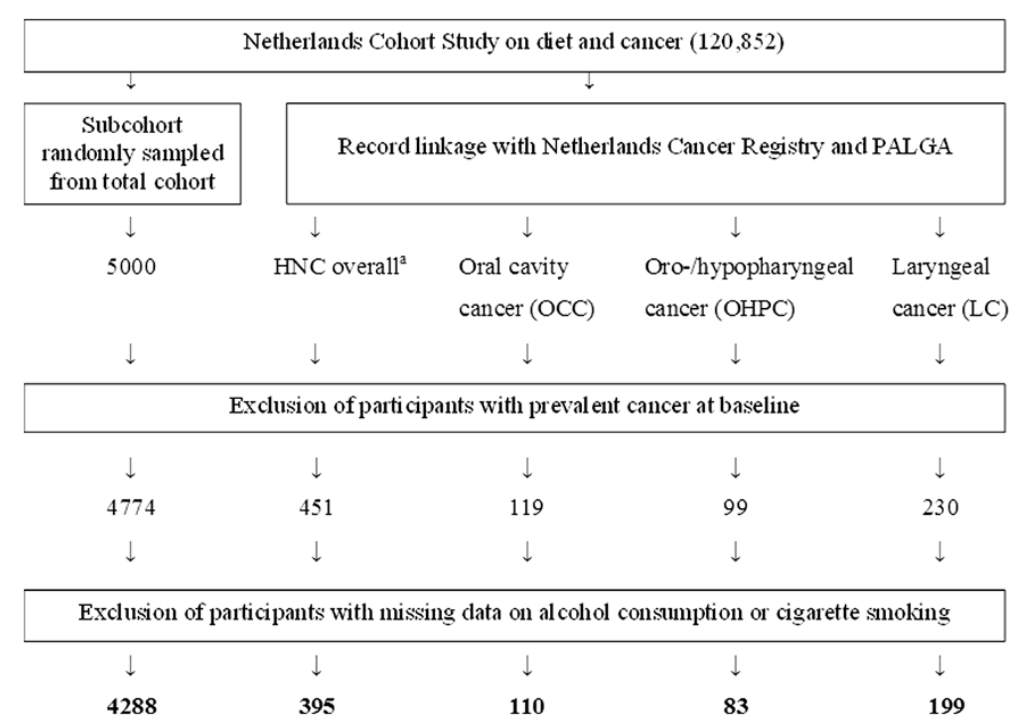

Figure 1 Flow diagram of the number of subcohort members and cases on whom the analyses were based. *PALGA: nationwide network and registry of histopathology and cytopathology in the Netherlands. ${ }^{2}$ Oral cavity cancer; oro-/hypopharyngeal cancer; oral cavity, pharynx unspecified or overlapping cancer; laryngeal cancer. 
We asked about the habitual intake of alcohol during the year preceding the start of the study, measured by six items: (1) beer; (2) red wine; (3) white wine; (4) sherry and other fortified wines; (5) liquor types containing on average 16\% alcohol; and (6) (Dutch) gin, brandy, and whisky. In addition, questions were asked about the frequency of consumption and the number of glasses consumed on each drinking occasion. For analysis, we combined (2), (3), and (4) into "wine", and (5) and (6) into "liquor". Total mean daily ethanol intake was calculated using the Dutch food-composition table [25]. On the basis of pilot study data, standard glass sizes were defined as $200 \mathrm{~mL}$ for beer, $105 \mathrm{~mL}$ for wine, and $45 \mathrm{~mL}$ for liquor, corresponding to $8 \mathrm{~g}, 10 \mathrm{~g}$, and $13 \mathrm{~g}$ of ethanol, respectively [26]. We also asked questions about the consumption of "beer" and "other alcoholic beverages" 5 years before baseline and selected participants with stable alcohol consumption to perform a sensitivity analysis [27]. Participants who indicated that they used alcoholic beverages never or less than once a month were considered abstainers.

We asked detailed information regarding cigarette smoking. Among others, questions were asked about whether the subject was a smoker at baseline; age at which they started and stopped smoking; the number of cigarettes smoked daily and the number of smoking years (excluding stopping periods). Based on these questions, the following variables were constructed for analysis: smoking status (never/former/current); current smoking (yes/no); frequency (cigarettes/day); duration (years); the number of pack-years; and time since smoking cessation (years). We also asked about cigar and pipe smoking and the use of smokeless tobacco. Participants who indicated they had never smoked cigarettes were considered never smokers.

The FFQ was validated against a 9-day diet record, and the Spearman correlation coefficient between the alcohol intake assessed by the questionnaire and that estimated by the diet record was 0.89 for all subjects and 0.85 for users of alcoholic beverages [28]. The reproducibility of the FFQ was assessed through annually repeated measurements in a subgroup of the subcohort and the test-retest correlation was 0.90 for alcohol intake; this correlation declined only 0.01-0.02 per year [29].

Data were key-entered and processed in a standardized manner, blinded with regard to case/subcohort status in order to minimize observer bias in coding and data interpretation.

\section{Data analysis}

Person-years at risk were calculated from baseline until diagnosis of $\mathrm{HNC}$, death, emigration, loss to follow-up or end of follow-up (i.e. 31 December 2003), whichever occurred first.
Age (years) and sex were considered predefined confounders. The potential confounders considered were $[3,30,31]$ : level of education, non-occupational physical activity, energy intake, coffee and tea consumption, intake of fruit, vegetables, fish, fat, red meat, meat products, and family history of head-neck cancer. Alcohol consumption and cigarette smoking were mutually adjusted in statistical models. A variable was considered a confounder if including it in the model changed the rate ratio (RR) for any of the cancer (sub-) types by $>10 \%$; according to this, none of the potential confounders was included in the final model.

The Cox proportional hazards model was used to estimate incidence RRs and corresponding 95\% confidence intervals (CI) for alcohol consumption and cigarette smoking in multivariable adjusted case-cohort analyses. Analyses were done using the Stata 11.2 statistical software package (StataCorp, College Station, Texas, USA). Standard errors were calculated using the robust HuberWhite sandwich estimator to account for additional variance introduced by sampling from the cohort; this method is equivalent to the variance-covariance estimator by Barlow [32]. The proportional hazards (PH) assumption was assessed using the scaled Schoenfeld residuals [33]. If there was an indication for violation of the assumption for a variable, we further investigated this by adding a time-varying covariate for that variable to the model.

We also analyzed beer, wine, and liquor consumption, adjusted for ethanol intake, to examine whether substances in alcoholic beverages, other than ethanol, have an effect on HNC-risk. In smoking analyses, different aspects of cigarette smoking were investigated and mutually adjusted for, in order to obtain a complete exposure model. The total number of cases that exclusively smoked cigar and/ or pipe or used smokeless tobacco was too low $(N<10)$ to further analyze associations with HNC-risk.

When adjusting for smoking frequency, duration, or pack-years, we centered these continuous variables as proposed by Leffondré et al. [34]

Tests for linear dose-response trends were assessed by fitting ordinal exposure variables as continuous terms. To evaluate possible multiplicative interaction between categories of alcohol consumption and cigarette smoking, we estimated RRs of HNC overall and all HNC-subtypes for combinations of these exposures. The interaction was investigated by including cross-product terms in the model and performing a Wald test. Two-sided $P$ values are reported throughout the article.

Tests for heterogeneity among HNC-subtypes were performed to investigate differences between HNC subtypes by a bootstrapping method developed for the case-cohort design [35]. For each bootstrap sample, X subcohort members were randomly drawn from the subcohort of $\mathrm{X}$ subjects and $\mathrm{Y}$ cases from the total of $\mathrm{Y}$ 
cases outside the subcohort, both with replacement, out of the dataset of $\mathrm{X}+\mathrm{Y}$ observations. The logHRs were obtained from this sample using Stata's competing risks procedure and recalculated for each bootstrap-replication. The confidence interval and $P$ value of the differences in hazard ratio of the subtypes were then calculated from the replicated statistics. Each bootstrap analysis was based on at least 1,000 replications [36].

\section{Results}

Compared to the subcohort, cases were more frequently men than women, and less often alcohol abstainers (Table 1). Among alcohol consumers, cases had a substantially higher alcohol intake and generally drank more beer, wine, and liquor than subcohort members. In both cases and subcohort members, men mostly consumed beer and liquor, whereas women drank more wine. With respect to cigarette smoking, cases were far more often current smokers and also smoked a substantially higher number of pack-years than subcohort members. Women were more often never smokers than men; among ever smokers, men generally smoked more pack-years than women, in cases and subcohort members.

\section{Alcohol consumption}

Alcohol consumption of $\geq 30$ grams (g) per day compared with abstinence was associated with a statistically significantly increased risk of $\mathrm{HNC}$ overall (multivariate $\mathrm{RR}=2.74,95 \%$ CI $1.85-4.06)$, OCC $(\mathrm{RR}=6.39,95 \% \mathrm{CI}$ 3.13-13.03), and OHPC (RR $=3.52,95 \%$ CI 1.69-7.36), but not $\mathrm{LC}(\mathrm{RR}=1.54,95 \%$ CI $0.91-2.60)$ (Table 2). A strong dose-response relationship $(P$ trend $<0.001)$ was found between categories of increasing alcohol consumption and HNC overall, OCC, and OHPC risk. A significant interaction was found between sex and continuous alcohol consumption in HNC overall $(P=0.02)$ and OCC $(P=0.004)$, with women having higher RRs than men.

After adjustment for total alcohol intake, consumption of beer, wine, and liquor was generally not significantly associated with HNC-risk. Beer consumption was, however, statistically significantly, positively associated with OHPC-risk ( $P$ trend $=0.03$ ); liquor consumption was significantly associated with an increased risk of OCC ( $P$ trend $=0.03$ ). Wine consumption was largely inversely associated - although not statistically significantly - with risk of HNC overall and HNC-subtypes.

Although risk rates clearly varied among HNC-subtypes, tests for heterogeneity did not show any significant risk differences, possibly due to low power.

\section{Cigarette smoking}

Current cigarette smoking was statistically significantly associated with risk of $\mathrm{HNC}$ overall (multivariate $\mathrm{RR}=$ $4.49,95 \%$ CI 3.11-6.48) and all subtypes, with strongest associations in OHPC ( $\mathrm{RR}=8.53,95 \%$ CI 3.38-21.55) and $\mathrm{LC}(\mathrm{RR}=8.07,95 \%$ CI 3.94-16.54), compared with never smoking (Table 3). Compared with never smoking, former cigarette smoking was also associated with risk of HNC overall, although not statistically significantly $(\mathrm{RR}=1.44,95 \% \mathrm{CI} 0.97-2.14)$, OHPC $(\mathrm{RR}=2.68$, 95\% CI 1.00-7.14), and LC ( $\mathrm{RR}=2.63,95 \%$ CI 1.26-5.47), but not $\mathrm{OCC}(\mathrm{RR}=0.70,95 \%$ CI $0.37-1.33)$. Frequency and duration of cigarette smoking were also strongly, statistically significantly associated with an increased risk of HNC overall, OHPC, and LC (Table 3).

Regarding different aspects of cigarette smoking, after mutual adjustment, cigarette smoking status, frequency, and duration all remained statistically significantly associated with risk of HNC overall, OHPC, and LC (see Additional file 1). After additional adjustment for alcohol consumption (Table 3), most RRs between cigarette smoking status, frequency, duration and risk of $\mathrm{HNC}$ (-subtypes) slightly attenuated, but remained statistically significantly associated with increased risks.

Results regarding smoking cessation show that the risk of $\mathrm{HNC}$ overall and all subtypes diminished for smokers who stopped smoking since $<10,10$ to $<20$, or $\geq 20$ years, compared with current smokers (all $P$ trend $<0.01$ ) (Table 3). Nevertheless, compared with never smokers, RRs 20 years after smoking cessation were still elevated for HNC overall, OHPC, and LC, although not statistically significantly.

Despite considerable differences in risk rates among HNC-subtypes, tests for heterogeneity only showed statistically significant risk rates for duration of cigarette smoking $(P<0.001)$ and time since smoking cessation $(P<0.001)$.

\section{Interaction between alcohol consumption and cigarette smoking}

For HNC overall, increased risks were found for every exposure combination of alcohol consumption and cigarette smoking, mostly statistically significantly, compared to never smokers and abstainers as reference group (Table 4). In addition, a statistically significant, positive, multiplicative interaction was found ( $P$ interaction 0.03 ) between categories of alcohol consumption and cigarette smoking, with a RR of 8.28 (95\% CI 3.98-17.22), comparing participants smoking $\geq 20$ cigarettes and drinking $\geq 30 \mathrm{~g}$ alcohol per day with never smokers abstaining from alcohol.

In HNC-subtypes, RRs were mostly increased as well when comparing participants smoking $\geq 20$ cigarettes and drinking $>15 \mathrm{~g}$ alcohol per day with never smokers consuming 0 to $15 \mathrm{~g}$ alcohol per day, with the highest RR for OHPC ( $R R=16.12,95 \%$ CI 4.31-60.27), but no significant interaction was found, possibly due to low numbers in strata. 
Table 1 Characteristics of cases and subcohort members in the Netherlands Cohort Study (NLCS), 1986 - 2003

\begin{tabular}{|c|c|c|c|c|c|}
\hline \multirow[b]{4}{*}{ Exposure variables and potential confounders } & \multirow{4}{*}{$\begin{array}{l}\text { Subcohort } \\
(N=4288)^{b}\end{array}$} & \multicolumn{4}{|c|}{ Head-neck cancer cases } \\
\hline & & \multirow{3}{*}{$\begin{array}{l}\text { Overall } \\
(N=395)^{b}\end{array}$} & \multicolumn{3}{|l|}{ Subtypes } \\
\hline & & & $\mathrm{OCC}^{\mathrm{a}}$ & OHPC $^{a}$ & $L C^{a}$ \\
\hline & & & $(N=110)^{b}$ & $\overline{(N=83)^{b}}$ & $(N=199)^{b}$ \\
\hline Age at baseline (years) & $61.3(4.2)^{c}$ & $61.8(4.1)$ & $61.8(4.3)$ & $61.5(4.2)$ & $61.8(4.0)$ \\
\hline Sex: men (\%) & 49.2 & 79.5 & 59.1 & 73.5 & 94.0 \\
\hline Abstainer from alcohol (\%) & 23.9 & 12.4 & 10.9 & 13.3 & 13.1 \\
\hline Men (\%) & 14.8 & 9.2 & 4.6 & 9.8 & 10.7 \\
\hline Women (\%) & 32.6 & 24.7 & 20.0 & $22.7^{d}$ & $50.0^{\mathrm{e}}$ \\
\hline \multicolumn{6}{|l|}{ Alcohol consumers: } \\
\hline Ethanol intake (grams/day) & $13.4(15.0)$ & $27.3(25.6)$ & $28.7(25.4)$ & $35.0(31.6)$ & $23.2(22.1)$ \\
\hline Men & 17.5 & 29.1 & 34.3 & 40.2 & 23.5 \\
\hline Women & 8.5 & 18.6 & 19.1 & 18.0 & 14.7 \\
\hline Beer intake (glasses/week) & $2.2(5.8)$ & $6.3(12.5)$ & $4.4(10.2)$ & $10.3(18.3)$ & $5.8(10.4)$ \\
\hline Men & 3.7 & 6.9 & 6.1 & 11.1 & 5.8 \\
\hline Women & 0.3 & 3.5 & 1.4 & 7.9 & 4.5 \\
\hline Wine intake (glasses/week) & $3.7(5.6)$ & $4.4(9.1)$ & $5.5(8.1)$ & $6.0(11.5)$ & $3.1(8.4)$ \\
\hline Men & 3.1 & 4.0 & 4.2 & 6.7 & 3.1 \\
\hline Women & 4.4 & 6.0 & 7.7 & 3.5 & 4.1 \\
\hline Liquor intake (glasses/week) & $2.9(5.7)$ & $7.3(10.0)$ & $8.4(11.2)$ & $7.7(11.7)$ & $6.4(8.3)$ \\
\hline Men & 4.6 & 8.2 & 11.5 & 9.4 & 6.6 \\
\hline Women & 0.9 & 3.0 & 3.1 & 1.9 & 1.9 \\
\hline \multicolumn{6}{|l|}{ Cigarette smoking status } \\
\hline \multicolumn{6}{|l|}{ Total } \\
\hline Never smokers (\%) & 36.9 & 11.1 & 26.4 & 7.2 & 4.5 \\
\hline Former smokers (\%) & 35.5 & 27.9 & 21.8 & 26.5 & 32.2 \\
\hline Current smokers (\%) & 27.6 & 61.0 & 51.8 & 66.3 & 63.3 \\
\hline \multicolumn{6}{|l|}{ Men } \\
\hline Never smokers (\%) & 13.8 & 6.7 & 16.9 & 4.9 & 3.7 \\
\hline Former smokers (\%) & 51.4 & 31.5 & 27.7 & 29.5 & 33.7 \\
\hline Current smokers (\%) & 34.8 & 61.8 & 55.4 & 65.6 & 62.6 \\
\hline \multicolumn{6}{|l|}{ Women } \\
\hline Never smokers (\%) & 59.4 & 28.4 & 40.0 & $13.6^{\mathrm{d}}$ & $16.7^{\mathrm{e}}$ \\
\hline Former smokers (\%) & 20.0 & 13.6 & 13.3 & 18.2 & 8.3 \\
\hline Current smokers (\%) & 20.6 & 58.0 & 46.7 & 68.2 & 75.0 \\
\hline \multicolumn{6}{|l|}{ Ever cigarette smokers: } \\
\hline Frequency of cigarette smoking ( $N /$ day) & $15.3(10.2)$ & $19.5(10.9)$ & $19.9(11.9)$ & $21.4(12.7)$ & $18.6(9.6)$ \\
\hline Men & 17.1 & 19.9 & 21.6 & 22.9 & 18.4 \\
\hline Women & 11.6 & 17.4 & 16.5 & 16.7 & 22 \\
\hline Duration of cigarette smoking (years) & $31.7(12.1)$ & $39.1(9.5)$ & $37.8(9.2)$ & $38.5(9.8)$ & $39.9(9.4)$ \\
\hline Men & 33.6 & 39.8 & 38.9 & 39.8 & 40.0 \\
\hline Women & 27.8 & 35.8 & 35.4 & 34.5 & 38.2 \\
\hline Pack-years of cigarette smoking $(N)$ & $22.8(17.7)$ & $34.4(20.9)$ & $34.5(23.5)$ & $37.0(23.2)$ & $33.5(18.9)$ \\
\hline Men & 26.2 & 35.7 & 38.5 & 40.5 & 33.2 \\
\hline Women & 16.0 & 28.3 & 26.4 & 26.3 & 38.5 \\
\hline
\end{tabular}


Table 1 Characteristics of cases and subcohort members in the Netherlands Cohort Study (NLCS), 1986 - 2003 (Continued)

\begin{tabular}{|c|c|c|c|c|c|}
\hline \multicolumn{6}{|l|}{ Level of education (\%) } \\
\hline Primary & 29.5 & 27.6 & 20.9 & 25.6 & 31.5 \\
\hline Lower vocational & 22.0 & 18.9 & 17.3 & 17.1 & 20.8 \\
\hline Secondary and medium vocational & 34.8 & 35.7 & 41.8 & 36.6 & 32.5 \\
\hline University and higher vocational & 13.8 & 17.9 & 20.0 & 20.7 & 15.2 \\
\hline
\end{tabular}

aCC: oral cavity cancer; OHPC: oro-/hypopharyngeal cancer; LC: laryngeal cancer.

${ }^{\mathrm{b}}$ The number of subcohort members or cases used in age- and sex-adjusted, multivariate analyses of alcohol consumption and cigarette smoking.

'Values are given as mean (SD); for categorical variables, $N(\%)$ is presented.

diased on only 22 female OHPC cases.

Based on only 12 female LC cases.

\section{Discussion}

In this large prospective study on alcohol consumption, cigarette smoking, and risk of $\mathrm{HNC}$ (-subtypes), alcohol consumption and cigarette smoking were strongly, independently associated with an increased risk of HNC overall. The strength of these associations however differed between HNC-subtypes; OCC was most strongly associated with alcohol consumption but most weakly with cigarette smoking, whereas LC was not statistically significantly associated with alcohol consumption. For HNC overall, a multiplicative interaction between categories of alcohol consumption and cigarette smoking was found.

\section{Alcohol consumption}

Our results are in agreement with those of previous studies, showing alcohol consumption to be an independent risk factor for the development of $\mathrm{HNC}$, with a strong, dose-response relationship $[4,9,11-14,17,23,37,38]$. Alcoholic beverages and acetaldehyde, the main metabolite of ethanol, are classified as a class I carcinogen [18]. It is plausible that alcohol - after being metabolized - acts both directly and indirectly in HNC carcinogenesis, the latter for example by acting as a solvent for other possible carcinogens, such as tobacco carcinogens [3,39].

The differential risk among HNC-subtypes is consistent with other studies, in which LC was also least associated with alcohol consumption $[8,40,41]$. However, several other studies found OHPC being most associated with alcohol consumption, although sometimes in specific subgroups, as opposed to OCC in our study [11,23,41]. Nevertheless, the differential risk among HNC-subtypes is likely to be explained by the larynx having the least direct exposure to alcohol compared with the oral cavity and pharynx $[39,42]$. The slightly increased RRs for alcohol consumption and LC may be due to inhalation of alcohol containing aerosols, silent aspiration, systemic effects, and possibly residual confounding.

After adjustment for total alcohol intake, we generally found similar risks between intake of beer, wine, liquor and HNC. These findings imply that ethanol itself probably is the most important factor in determining HNCrisk, rather than other substances in alcoholic beverages, which is in line with the results from other studies $[3,11,42]$. Consumption of wine was, however, generally inversely associated with HNC-risk, as was also shown in a pooled analysis [42], which could be due to residual confounding by a general healthier lifestyle of wineconsumers in our study population $[3,42,43]$.

The significantly higher RRs between alcohol consumption and $\mathrm{HNC}$ risk in women as compared with men were seen earlier and could possibly be explained by women having stronger carcinogenic effects of alcohol at the same exposure level, suggesting possible gender-specific risk or protective factors [11].

\section{Cigarette smoking}

This study confirms the strong associations of cigarette smoking with increased risk of HNC overall and all subtypes $[3,5,7,10,14,23,37,41]$. Among subtypes, however, OCC was least associated with cigarette smoking, and strongest associations were found with OHPC and LC. In addition, smoking status, frequency, and duration all appear to be of importance in the association between cigarette smoking and risk of HNC overall, OHPC, and LC. These results are generally consistent with previous reviews showing that cigarette smoking has a stronger effect on the larynx and/or pharynx than on the oral cavity $[7,8,10,23,41]$; in two meta-analyses, the larynx seemed to be clearly most susceptible to the effects of cigarette smoking $[23,41]$. A possible explanation for this could be the aerodynamics of respiratory flow in the upper airway: this flow changes from laminar in the oral cavity to turbulent in the larynx, which may result in the larynx and pharynx having a higher exposure to inhaled air - and thus to cigarette smoke - than the oral cavity.

Finally, our study shows smoking cessation leads to decreased HNC-risks, which is in line with results from a recent pooled analysis as well [44]. 
Table 2 Associations (multivariable ${ }^{a}$ adjusted incidence RRs) between alcohol consumption and risk of subtypes of head-neck cancer; Netherlands Cohort Study (NLCS), 1986 - 2003

\begin{tabular}{|c|c|c|c|c|c|c|c|c|c|c|c|}
\hline & \multirow[b]{4}{*}{$\begin{array}{l}\text { Categorical } \\
\text { median }\end{array}$} & \multirow{4}{*}{$\begin{array}{l}\text { Subcohort } \\
\\
\text { Person time } \\
\text { at risk (years) }\end{array}$} & \multicolumn{9}{|c|}{ Head-neck cancer cases } \\
\hline & & & \multicolumn{2}{|l|}{ Overall } & \multicolumn{7}{|l|}{ Subtypes } \\
\hline & & & \multirow[b]{2}{*}{ No. of cases } & \multirow[b]{2}{*}{ RR $(95 \% \mathrm{Cl})$} & \multicolumn{2}{|l|}{$\mathrm{OCC}^{\mathbf{b}}$} & \multicolumn{2}{|l|}{ OHPC $^{\mathbf{b}}$} & \multicolumn{2}{|l|}{$L C^{b}$} & \multirow[b]{2}{*}{$\begin{array}{l}P \text { for } \\
\text { heterogeneity }\end{array}$} \\
\hline & & & & & No. of cases & $\mathrm{RR}(95 \% \mathrm{Cl})$ & No. of cases & RR $(95 \% \mathrm{Cl})$ & No. of cases & RR $(95 \% \mathrm{Cl})$ & \\
\hline \multicolumn{12}{|c|}{ Alcohol consumption (grams ethanol/day) } \\
\hline Abstainers & 0 & 15255 & 49 & 1 (reference) & 12 & 1 (reference) & 11 & 1 (reference) & 26 & 1 (reference) & 0.86 \\
\hline$>0$ to $<5$ & 2 & 19008 & 67 & $1.11(0.75-1.65)$ & 17 & $1.25(0.59-2.65)$ & 14 & $1.06(0.47-2.40)$ & 36 & $1.03(0.60-1.77)$ & \\
\hline 5 to $<15$ & 9 & 14468 & 72 & $1.15(0.77-1.71)$ & 19 & $1.91(0.91-4.03)$ & 12 & $0.90(0.38-2.13)$ & 40 & $0.94(0.56-1.58)$ & \\
\hline 15 to $<30$ & 22 & 9961 & 92 & $1.52(1.02-2.27)$ & 30 & $3.88(1.86-8.12)$ & 13 & $0.99(0.41-2.38)$ & 49 & $1.10(0.66-1.83)$ & \\
\hline$\geq 30$ & 40 & 5659 & 115 & $2.74(1.85-4.06)$ & 32 & $6.39(3.13-13.03)$ & 33 & $3.52(1.69-7.36)$ & 48 & $1.54(0.91-2.60)$ & \\
\hline$P$ for trend ${ }^{c}$ & & & & $<0.001$ & & $<0.001$ & & $<0.001$ & & 0.05 & \\
\hline \multicolumn{12}{|l|}{ Continuous, 10 gram } \\
\hline \multicolumn{12}{|l|}{ ethanol/day increments } \\
\hline Overall & & 64352 & 395 & $1.20(1.12-1.27)$ & 110 & $1.28(1.18-1.39)$ & 83 & $1.27(1.16-1.38)$ & 199 & $1.10(1.02-1.18)$ & 0.18 \\
\hline Men & & 30169 & 314 & $1.19(1.12-1.27)$ & 65 & $1.27(1.17-1.38)$ & 61 & $1.27(1.16-1.39)$ & 187 & $1.10(1.03-1.19)$ & \\
\hline Women & & 34183 & 81 & $1.40(1.18-1.65)$ & 45 & $1.58(1.33-1.87)$ & 22 & $1.31(0.91-1.87)$ & 12 & $0.85(0.46-1.59)$ & \\
\hline$P$ for interaction ${ }^{d}$ & & & & 0.02 & & 0.004 & & 0.68 & & 0.67 & \\
\hline \multicolumn{12}{|c|}{ Alcohol consumption (grams ethanol/day) stable users ${ }^{e}$} \\
\hline Abstainers & 0 & 11810 & 38 & 1 (reference) & 9 & 1 (reference) & 9 & 1 (reference) & 20 & 1 (reference) & 1.00 \\
\hline$>0$ to $<5$ & 2 & 11813 & 36 & $0.98(0.60-1.61)$ & 12 & $1.65(0.68-4.01)$ & 7 & $0.86(0.30-2.41)$ & 17 & $0.72(0.35-1.46)$ & \\
\hline 5 to $<15$ & 9 & 8749 & 38 & $0.96(0.58-1.59)$ & 9 & $1.68(0.63-4.47)$ & 8 & $0.89(0.32-2.47)$ & 21 & $0.72(0.37-1.40)$ & \\
\hline 15 to $<30$ & 22 & 5293 & 45 & $1.27(0.76-2.11)$ & 12 & $3.20(1.25-8.19)$ & 6 & $0.72(0.23-2.26)$ & 27 & $0.96(0.50-1.83)$ & \\
\hline$\geq 30$ & 42 & 3047 & 69 & $2.90(1.78-4.73)$ & 17 & $7.50(3.15-17.88)$ & 20 & $3.46(1.46-8.20)$ & 31 & $1.57(0.82-3.02)$ & \\
\hline$P$ for trend & & & & $<0.001$ & & $<0.001$ & & 0.001 & & 0.03 & \\
\hline Continuous, 10 grams & & 39712 & 226 & $1.26(1.16-1.36)$ & 59 & $1.37(1.24-1.52)$ & 50 & $1.35(1.20-1.52)$ & 116 & $1.16(1.04-1.28)$ & 0.72 \\
\hline \multicolumn{12}{|l|}{ ethanol/day increments } \\
\hline \multicolumn{12}{|c|}{ Alcoholic beverages (glasses/day) ${ }^{f}$} \\
\hline \multicolumn{12}{|l|}{ Beer } \\
\hline No beer & 0 & 43519 & 183 & 1 (reference) & 59 & 1 (reference) & 36 & 1 (reference) & 87 & 1 (reference) & 0.84 \\
\hline$>0-<1$ & 0.2 & 16408 & 129 & $0.94(0.71-1.24)$ & 34 & $1.10(0.65-1.86)$ & 24 & $0.98(0.54-1.76)$ & 69 & $0.85(0.60-1.22)$ & \\
\hline $1-<2$ & 1.4 & 2853 & 37 & $1.12(0.72-1.74)$ & 8 & $1.17(0.49-2.77)$ & 6 & $1.04(0.41-2.66)$ & 23 & $1.19(0.71-2.01)$ & \\
\hline
\end{tabular}


Table 2 Associations (multivariable ${ }^{a}$ adjusted incidence RRs) between alcohol consumption and risk of subtypes of head-neck cancer; Netherlands Cohort Study (NLCS), 1986 - 2003 (Continued)

\begin{tabular}{|c|c|c|c|c|c|c|c|c|c|c|c|}
\hline$\geq 2$ & 3.4 & 1554 & 46 & $1.39(0.83-2.34)$ & 9 & $0.99(0.34-2.82)$ & 17 & $2.48(1.03-5.98)$ & 20 & $1.30(0.69-2.46)$ & \\
\hline$P$ for trend & & & & 0.14 & & 0.95 & & 0.03 & & 0.20 & \\
\hline Continuous, 1 & & 64335 & 395 & $1.07(0.97-1.19)$ & 110 & $0.97(0.80-1.16)^{9}$ & 83 & $1.19(1.01-1.40)$ & 199 & $1.08(0.96-1.23)$ & 0.07 \\
\hline \multicolumn{12}{|c|}{ glass/day increments } \\
\hline \multicolumn{12}{|l|}{ Wine } \\
\hline No wine & 0 & 30263 & 197 & 1 (reference) & 44 & 1 (reference) & 38 & 1 (reference) & 114 & 1 (reference) & 0.93 \\
\hline$>0-<1$ & 0.2 & 25975 & 132 & $0.88(0.67-1.14)$ & 40 & $1.07(0.67-1.71)$ & 33 & $1.01(0.59-1.75)$ & 57 & $0.74(0.52-1.05)$ & \\
\hline $1-<2$ & 1.4 & 5277 & 39 & $0.95(0.63-1.44)$ & 14 & $1.31(0.67-2.55)$ & 5 & $0.52(0.19-1.39)$ & 20 & $1.07(0.63-1.83)$ & \\
\hline$\geq 2$ & 2.6 & 2751 & 24 & $0.56(0.29-1.07)$ & 11 & $0.93(0.34-2.57)$ & 7 & $0.52(0.15-1.81)^{\mathrm{g}}$ & 6 & $0.39(0.15-0.99)$ & \\
\hline$P$ for trend & & & & 0.15 & & 0.93 & & 0.16 & & 0.21 & \\
\hline Continuous, 1 & & 64265 & 392 & $0.88(0.74-1.05)$ & 109 & $0.89(0.69-1.16)$ & 83 & $0.86(0.64-1.17)$ & 197 & $0.88(0.68-1.14)$ & 0.26 \\
\hline \multicolumn{12}{|c|}{ glass/day increments } \\
\hline \multicolumn{12}{|l|}{ Liquor } \\
\hline No liquor & 0 & 33299 & 137 & 1 (reference) & 40 & 1 (reference) & 34 & 1 (reference) & 63 & 1 (reference) & 0.44 \\
\hline$>0-<1$ & 0.2 & 23492 & 133 & 1.09 (0.84-1.43) & 31 & $1.10(0.67-1.80)$ & 23 & $0.86(0.48-1.53)$ & 78 & $1.17(0.81-1.67)$ & \\
\hline $1-<2$ & 1.9 & 5370 & 67 & $1.09(0.76-1.57)$ & 18 & $1.65(0.87-3.15)$ & 12 & $0.79(0.39-1.62)$ & 37 & $1.08(0.67-1.74)$ & \\
\hline$\geq 2$ & 2.8 & 2115 & 56 & $1.18(0.71-1.95)$ & 20 & $2.26(1.02-4.99)$ & 14 & $0.83(0.33-2.13)$ & 20 & $0.95(0.47-1.93)$ & \\
\hline$P$ for trend & & & & 0.61 & & 0.03 & & 0.64 & & 0.83 & \\
\hline Continuous, 1 & & 64275 & 393 & $1.01(0.86-1.18)$ & 109 & $1.18(0.89-1.56)$ & 83 & $0.89(0.68-1.15)$ & 198 & $0.98(0.80-1.21)$ & 0.25 \\
\hline \multicolumn{12}{|c|}{ glass/day increments } \\
\hline
\end{tabular}

Proportional hazards assumption was possibly violated for the exposure variable, and there was a statistically significant interaction with time. 
Table 3 Associations (multivariable a adjusted incidence RRs) between cigarette smoking and risk of subtypes of head-neck cancer; Netherlands Cohort Study (NLCS), 1986 - 2003

\begin{tabular}{|c|c|c|c|c|c|c|c|c|c|c|c|}
\hline & \multirow[b]{4}{*}{$\begin{array}{l}\text { Categorical } \\
\text { median }\end{array}$} & \multirow{4}{*}{$\begin{array}{l}\text { Subcohort } \\
\\
\text { Person time } \\
\text { at risk (years) }\end{array}$} & \multicolumn{9}{|c|}{ Head-neck cancer cases } \\
\hline & & & \multicolumn{2}{|c|}{ Overall } & \multicolumn{7}{|c|}{ Subtypes } \\
\hline & & & \multirow[b]{2}{*}{$\begin{array}{l}\text { No. of } \\
\text { cases }\end{array}$} & \multirow[b]{2}{*}{ RR $(95 \%$ Cl) } & \multicolumn{2}{|l|}{$\mathrm{OCC}^{\mathrm{b}}$} & \multicolumn{2}{|l|}{ OHPC $^{\mathbf{b}}$} & \multicolumn{2}{|l|}{$\mathrm{LC}^{\mathbf{b}}$} & \multirow[b]{2}{*}{$\begin{array}{l}P \text { for } \\
\text { heterogeneity }\end{array}$} \\
\hline & & & & & $\begin{array}{l}\text { No. of } \\
\text { cases }\end{array}$ & RR $(95 \% \mathrm{Cl})$ & $\begin{array}{l}\text { No. of } \\
\text { cases }\end{array}$ & RR $(95 \%$ Cl) & $\begin{array}{l}\text { No. of } \\
\text { cases }\end{array}$ & RR $(95 \%$ Cl) & \\
\hline \multicolumn{12}{|l|}{ Cigarette smoking status } \\
\hline Never smokers & & 25051 & 44 & 1 (reference) & 29 & 1 (reference) & 6 & 1 (reference) & 9 & 1 (reference) & 0.97 \\
\hline Former smokers & & 22644 & 110 & $1.44(0.97-2.14)$ & 24 & $0.70(0.37-1.33)$ & 22 & $2.68(1.00-7.14)^{i}$ & 64 & $2.63(1.26-5.47)$ & \\
\hline Current smokers & & 16657 & 241 & $4.49(3.11-6.48)$ & 57 & $2.11(1.23-3.62)$ & 55 & $8.53(3.38-21.55)$ & 126 & $8.07(3.94-16.54)$ & \\
\hline$P$ for trend ${ }^{c}$ & & & & $<0.001$ & & 0.001 & & $<0.001$ & & $<0.001$ & \\
\hline$P$ for interaction with sex ${ }^{d}$ & & & & 0.25 & & 0.08 & & 0.44 & & 0.46 & \\
\hline \multicolumn{12}{|c|}{ Cigarette smoking status, additionally adjusted for frequency and duration of cigarette smoking ${ }^{e}$} \\
\hline Never smokers & & 25051 & 44 & 1 (reference) & 29 & 1 (reference) & 6 & 1 (reference) & 9 & 1 (reference) & 0.97 \\
\hline Former smokers & & 22644 & 110 & $1.64(1.08-2.49)$ & 24 & $0.79(0.40-1.58)$ & 22 & $3.03(1.09-8.45)$ & 64 & $2.87(1.34-6.13)$ & \\
\hline Current smokers & & 16657 & 241 & $3.51(2.36-5.23)$ & 57 & $1.91(1.06-3.42)$ & 55 & $7.49(2.87-19.54)$ & 126 & $5.26(2.45-11.28)$ & \\
\hline$P$ for trend & & & & $<0.001$ & & 0.03 & & $<0.001$ & & $<0.001$ & \\
\hline \multicolumn{12}{|l|}{ Frequency of cigarette smoking $(\mathrm{N} / \text { day })^{f}$} \\
\hline Never smokers & 0 & 25051 & 44 & 1 (reference) & 29 & 1 (reference) & 6 & 1 (reference) & 9 & 1 (reference) & 0.99 \\
\hline$>0$ to $<20$ & 10 & 24787 & 155 & $1.30(0.84-2.01)$ & 38 & $0.63(0.30-1.32)$ & 30 & $2.08(0.73-5.94)$ & 85 & $2.32(1.07-5.04)$ & \\
\hline$\geq 20$ & 20 & 14514 & 196 & $2.23(1.45-3.44)$ & 43 & $1.06(0.52-2.16)$ & 47 & $4.67(1.64-13.34)$ & 105 & $3.75(1.73-8.14)$ & \\
\hline$P$ for trend & & & & $<0.001$ & & 0.33 & & $<0.001$ & & $<0.001$ & \\
\hline Continuous, 10 cigarettes/day increments & & 64352 & 395 & $1.25(1.13-1.38)$ & 110 & $1.20(1.00-1.44)^{j}$ & 83 & $1.42(1.20-1.69)$ & 199 & $1.21(1.08-1.36)$ & 0.71 \\
\hline \multicolumn{12}{|l|}{ Duration of cigarette smoking (years) } \\
\hline Never smokers & 0 & 25051 & 44 & 1 (reference) & 29 & 1 (reference) & 6 & 1 (reference) & 9 & 1 (reference) & $<0.001$ \\
\hline$>0$ to $<20$ & 13 & 7433 & 20 & $1.00(0.56-1.77)$ & 4 & $0.38(0.13-1.17)$ & 5 & $2.11(0.59-7.51)$ & 11 & $1.88(0.75-4.69)$ & \\
\hline 20 to $<40$ & 30 & 18999 & 105 & $1.44(0.95-2.21)$ & 30 & $0.80(0.41-1.59)$ & 25 & $2.74(0.98-7.68)$ & 50 & $2.35(1.09-5.06)$ & \\
\hline$\geq 40$ & 43 & 12868 & 226 & $2.45(1.49-4.02)$ & 47 & $0.98(0.39-2.46)$ & 47 & $3.89(1.22-12.40)$ & 129 & $4.81(2.11-11.00)$ & \\
\hline$P$ for trend & & & & $<0.001$ & & 0.87 & & 0.02 & & $<0.001$ & \\
\hline Continuous, 10 years increments & & 64352 & 395 & $1.28(1.14-1.42)$ & 110 & $1.03(0.85-1.24)$ & 83 & $1.36(1.09-1.70)$ & 199 & $1.49(1.25-1.78)$ & 0.25 \\
\hline \multicolumn{12}{|l|}{ Pack-years of cigarette smoking ${ }^{h}$} \\
\hline Never smokers & 0 & 25051 & 44 & 1 (reference) & 29 & 1 (reference) & 6 & 1 (reference) & 9 & 1 (reference) & 1.00 \\
\hline$>0$ to $<20$ & 9 & 20832 & 96 & $1.16(0.77-1.76)$ & 24 & $0.58(0.30-1.14)$ & 20 & $2.12(0.77-5.80)$ & 51 & $2.07(0.97-4.41)$ & \\
\hline
\end{tabular}


Table 3 Associations (multivariable ${ }^{a}$ adjusted incidence RRs) between cigarette smoking and risk of subtypes of head-neck cancer; Netherlands Cohort Study (NLCS), 1986 - 2003 (Continued)

\begin{tabular}{|c|c|c|c|c|c|c|c|c|c|c|c|}
\hline 20 to $<40$ & 28 & 12732 & 132 & $1.65(1.04-2.60)$ & 32 & $0.84(0.39-1.83)$ & 26 & $2.87(0.94-8.79)$ & 73 & $2.93(1.33-6.48)$ & \\
\hline$\geq 40$ & 48 & 5736 & 123 & $2.82(1.76-4.50)$ & 25 & $1.28(0.58-2.82)$ & 31 & $6.49(2.11-19.95)$ & 66 & $4.79(2.15-10.64)$ & \\
\hline$P$ for trend & & & & $<0.001$ & & 0.07 & & $<0.001$ & & $<0.001$ & \\
\hline Continuous, 10 pack-years increments & & 64352 & 395 & $1.18(1.11-1.25)$ & 110 & $1.16(1.04-1.28)$ & 83 & $1.24(1.12-1.36)$ & 199 & $1.16(1.09-1.24)$ & 0.77 \\
\hline \multicolumn{12}{|l|}{ Cigarette smoking cessation ${ }^{i}$} \\
\hline Never smokers & 25 & 25051 & 44 & 1 (reference) & 29 & 1 (reference) & 6 & 1 (reference) & 9 & 1 (reference) & $<0.001$ \\
\hline Stopped $\geq 20$ years & 14 & 6953 & 24 & $1.25(0.72-2.19)$ & 5 & $0.63(0.22-1.81)$ & 6 & $3.35(0.97-11.55)$ & 13 & $1.92(0.79-4.70)$ & \\
\hline Stopped 10 to $<20$ years & 5 & 7717 & 36 & $1.49(0.91-2.43)$ & 8 & $0.78(0.32-1.86)$ & 8 & $3.29(1.04-10.39)$ & 20 & $2.45(1.07-5.61)^{k}$ & \\
\hline Stopped $>0$ to $<10$ years & 0 & 7918 & 50 & $1.73(1.09-2.76)$ & 11 & $0.84(0.39-1.83)$ & 8 & $2.48(0.77-7.93)$ & 31 & $3.45(1.56-7.62)$ & \\
\hline Current smokers & & 16657 & 241 & $4.26(2.93-6.20)$ & 57 & $2.03(1.16-3.56)$ & 55 & $8.10(3.14-20.87)$ & 126 & $7.53(3.65-15.51)$ & \\
\hline$P$ for trend & & & & $<0.001$ & & 0.004 & & $<0.001$ & & $<0.001$ & \\
\hline
\end{tabular}

${ }^{a}$ All analyses were adjusted for age (years), sex, and alcohol consumption ( $g$ ethanol/day; continuous)

bOCC: oral cavity cancer; OHPC: oro-/hypopharyngeal cancer; LC: laryngeal cancer.

'Tests for dose-response trends were assessed by fitting ordinal variables as continuous terms in the Cox proportional hazards model.

${ }^{\mathrm{d}} P$ Value for interaction between sex and cigarette smoking status, based on cross-product terms in the Cox proportional hazards model and Wald test.

'Additionally adjusted for frequency ( $N /$ day; continuous; centered) and duration of cigarette smoking (years; continuous; centered).

${ }^{\mathrm{f}}$ Analyses of cigarette smoking frequency were additionally adjusted for current cigarette smoking and duration of cigarette smoking (years; continuous; centered).

${ }^{9}$ Analyses of cigarette smoking duration were additionally adjusted for current cigarette smoking and frequency of cigarette smoking ( $N /$ day; continuous; centered).

${ }^{\mathrm{h}}$ Analyses of cigarette smoking pack-years were additionally adjusted for current cigarette smoking.

'Cigarette smoking cessation was additionally adjusted for the no. of cigarette pack-years (continuous; centered).

$\mathrm{j}_{\mathrm{i}}<0.05$.

${ }^{k}$ Proportional hazards assumption was possibly violated for the exposure variable, and there was a statistically significant interaction with time. 
Table 4 Combinations of categories of alcohol consumption and cigarette smoking and risk (multivariable adjusted incidence RRs) of subtypes of head-neck cancer; Netherlands Cohort Study (NLCS), 1986 - 2003

\begin{tabular}{|c|c|c|c|c|c|c|c|c|c|c|c|}
\hline & \multicolumn{11}{|c|}{ Head-neck cancer cases } \\
\hline & \multicolumn{5}{|l|}{ Overall } & \multicolumn{6}{|l|}{ Subtypes } \\
\hline & & & & & & $\mathrm{OCC}^{\mathrm{b}}$ & & OHPC $^{\mathbf{b}}$ & & $\mathrm{LC}^{\mathbf{b}}$ & \\
\hline & \multicolumn{5}{|c|}{ Alcohol consumption (grams ethanol/day) } & \multicolumn{2}{|c|}{ Alcohol consumption $^{c}$} & \multicolumn{2}{|c|}{ Alcohol consumption ${ }^{c}$} & \multicolumn{2}{|c|}{ Alcohol consumption ${ }^{c}$} \\
\hline & 0 & $>0$ to $<5$ & 5 to $<15$ & 15 to $<30$ & $\geq 30$ & $0-15$ & $>15$ & $0-15$ & $>15$ & $0-15$ & $>15$ \\
\hline \multicolumn{12}{|c|}{ Frequency of cigarette smoking ( $N /$ day) } \\
\hline \multicolumn{12}{|l|}{ Never smokers } \\
\hline Cases/person time at risk ${ }^{d}$ & $10 / 8959$ & $13 / 9729$ & $7 / 4245$ & $11 / 1499$ & $3 / 619$ & $21 / 22933$ & $8 / 2118$ & $3 / 22933$ & $3 / 2118$ & 6/22933 & $3 / 2118$ \\
\hline RR & 1 (ref) & 1.20 & 1.23 & 5.53 & 2.97 & 1 (ref) & 4.16 & 1 (ref) & 10.18 & 1 (ref) & 3.05 \\
\hline $95 \% \mathrm{Cl}$ & & $0.52-2.75$ & $0.46-3.29$ & $2.27-13.49$ & $0.78-11.40$ & & $1.82-9.52$ & & $2.03-51.06$ & & $0.72-12.92$ \\
\hline \multicolumn{12}{|l|}{$>0$ to $<20$} \\
\hline Cases/person time at risk & $21 / 4194$ & $25 / 6534$ & $37 / 7061$ & $40 / 4814$ & $32 / 2184$ & 20/17789 & 18/6998 & 18/17789 & $12 / 6998$ & $44 / 17789$ & $41 / 6998$ \\
\hline RR & 1.89 & 1.56 & 2.04 & 2.63 & 3.81 & 0.76 & 1.55 & 4.02 & 5.63 & 2.66 & 4.19 \\
\hline $95 \% \mathrm{Cl}$ & $0.83-4.34$ & $0.71-3.41$ & $0.95-4.40$ & $1.22-5.67$ & $1.71-8.51$ & $0.34-1.71$ & $0.66-3.62$ & $1.07-15.14$ & $1.44-22.00$ & $1.03-6.86$ & $1.60-11.02$ \\
\hline \multicolumn{12}{|l|}{$\geq 20$} \\
\hline Cases/person time at risk & $18 / 2102$ & $29 / 2745$ & 28/3162 & $41 / 3648$ & $80 / 2856$ & $7 / 8010$ & $36 / 6504$ & $16 / 8010$ & $31 / 6504$ & $52 / 8010$ & $53 / 6504$ \\
\hline RR & 2.78 & 3.88 & 2.85 & 3.32 & 8.28 & 0.58 & 3.54 & 7.26 & 16.12 & 5.42 & 5.54 \\
\hline $95 \% \mathrm{Cl}$ & $1.18-6.54$ & $1.77-8.49$ & $1.28-6.34$ & $1.52-7.25$ & $3.98-17.22$ & $0.21-1.58$ & $1.66-7.52$ & $1.86-28.44$ & $4.31-60.27$ & $2.10-13.98$ & $2.15-14.27$ \\
\hline$P$ for interaction ${ }^{\mathrm{e}}$ & & & & & 0.03 & & 0.10 & & 0.09 & & 0.19 \\
\hline
\end{tabular}

${ }^{a}$ Adjusted for age, sex, current cigarette smoking, and duration of cigarette smoking (years; continuous; centered).

bOCC: oral cavity cancer; OHPC: oro-/hypopharyngeal cancer; LC: laryngeal cancer.

${ }^{{ }^{C}}$ For the categorical interaction analyses in HNC-subtypes, it was necessary to aggregate categories of alcohol consumption (grams ethanol/day) in order to obtain sufficient numbers in strata.

dPerson time at risk in years.

${ }^{\mathrm{e}} P$ Value for interaction between categories of alcohol consumption and cigarette smoking, based on cross-product terms in the Cox proportional hazards model and Wald test. 


\section{Interaction between alcohol consumption and cigarette smoking}

Our study confirms a multiplicative interaction between categories of alcohol consumption and cigarette smoking in $\mathrm{HNC}$ overall $[9,14,16-18,37,38,41]$. The interaction effect between alcohol consumption and cigarette smoking is biologically plausible, since alcohol can act as a solvent for carcinogens in cigarette smoke and make the mucosa more permeable for these carcinogens; as a result, the carcinogenic properties of both factors are likely to be enhanced in the presence of one another [3,39]. Still, in HNC-subtypes, we had low numbers of cases in strata, which probably resulted in limited power to detect a significant deviation from the multiplicative model.

\section{Strengths and limitations}

Important strengths of our study are the prospective character and completeness of follow-up. Our study is the second largest prospective cohort study investigating alcohol consumption and cigarette smoking on the risk of HNC overall and subtypes so far [9-15]. Furthermore, we were able to take into account data on smoking duration, and to investigate as well as adjust for several aspects of smoking behavior.

A possible limitation of our study is the single measurement of exposure data. Alcohol consumption and cigarette smoking were however extensively addressed in the questionnaire, with questions about lifetime exposure history of smoking and alcohol intake 5 years before baseline. It is however possible that participants who smoked at baseline in 1986 stopped smoking at some point during follow-up or changed their alcohol intake, and this may have led to bias due to misclassification. Furthermore, although our study includes a large number of cases, a lack of power is a possible explanation for finding non-significant results for some associations and the tests for heterogeneity.

We lack information on human papillomavirus (HPV) infection. HPV-infection is associated with HNC-risk $[45,46]$, but mainly with OHPC, in particular tonsil cancer and cancer of the base of the tongue. According to rates in our university medical center, only $25 \%$ of the diagnosed and treated oropharyngeal cancers between 1997 and 2003 were HPV-positive (all oropharyngeal cancer cases have been analyzed by p16-immunostaining and HPV16-specific fluorescence in situ hybridization (FISH), and - if FISH was negative - HPV-specific polymerase chain reaction). Moreover, the role of HPV in HNC-carcinogenesis is mainly of importance in young HNC-patients, and has increased since 1990 [47-49]. Since our participants were aged 55-69 years at baseline in 1986, we assume that the number of HPV-associated HNC cases in our cohort is low, and we expect potential bias due to possible misclassification to be very limited.
Other factors we did not take into account in our analyses are the use of drugs and oral hygiene. Although we investigated several potential confounders, residual confounding is still possible, but we presume this to be limited as well.

It might also be interesting to examine the RRs of HNC for smokers among non-drinkers and for drinkers among non-smokers. However, as the case numbers for these subgroups would be too small to analyze, we decided not to investigate this.

Finally, though we wanted to examine the role of alcohol consumption and cigarette smoking in HNC-subtypes, we did not investigate HNC located in the major salivary glands, nasal cavity, paranasal sinuses, and nasopharynx, because of low numbers of these cases as well as a presumably different etiology [50].

\section{Conclusions}

In conclusion, the present study, which is the second largest prospective cohort study regarding this topic so far, confirms the principal role of alcohol consumption and cigarette smoking in HNC-carcinogenesis, as well as the differential associations with HNC-subtypes, and a significant, positive, multiplicative interaction between both factors. As the existing evidence is largely based on casecontrol studies, this cohort study contributes to establish in which extent alcohol consumption and cigarette smoking are associated with risk of HNC overall and, more specifically, HNC-subtypes.

\section{Additional file}

Additional file 1: Table A1. Age- and sex-adjusted associations (incidence RRs) between cigarette smoking and risk of subtypes of headneck cancer; Netherlands Cohort Study (NLCS), 1986 - 2003. Table A2. Associations (multivariable adjusted incidence RRs) between cigarette smoking and risk of subtypes of head-neck cancer, with (mutual) adjustment for smoking aspects; Netherlands Cohort Study (NLCS), 1986 - 2003.

\section{Abbreviations}

$\mathrm{Cl}$ : Confidence interval; FFQ: Food frequency questionnaire;

FISH: Fluorescence in situ hybridization; HNC: Head and neck cancer; HPV: Human papillomavirus; LC: Laryngeal cancer; NLCS: Netherlands Cohort Study; OCC: Oral cavity cancer; OHPC: Oro-/hypopharyngeal cancer; $\mathrm{PH}$ : Proportional hazards; RR: Rate ratio.

\section{Competing interests}

The authors declare that they have no competing interests.

\section{Authors' contributions}

The Netherlands Cohort Study was set up by PAvdB and RAG. All authors participated in the analysis and interpretation of data; DHEM carried out the statistical analyses. DHEM drafted the initial manuscript, and PAvdB, BK, RAG, and $\amalg S$ were involved in revising it. All authors read and approved the final manuscript. PAvdB, BK, and LJS were involved in the acquisition of funding for the study.

\section{Acknowledgements}

The authors wish to thank the participants of this study, The Netherlands Cancer Registry (IKNL and IKZ), and the nationwide network and registry of 
histopathology and cytopathology in the Netherlands (PALGA). They also thank Dr. A. Kester, Dr. A. Volovics, and Dr. A. Keszei for statistical advice; S. van de Crommert, J. Nelissen, A. Pisters, and C. de Zwart from Maastricht University, and H. Brants from the Dutch National Institute for Public Health, for assistance; and Ellen Dutman from TNO and J. Berben, H. van Montfort, and R. Schmeitz from Maastricht University for programming assistance.

\section{Grants}

This work was supported by World Cancer Research Fund International (WCRF) and Wereld Kanker Onderzoek Fonds (WCRF NL) [grant number 2010/253]. The funding body was not involved in design, collection, analysis, and interpretation of data; in the writing of the manuscript; and in the decision to submit the manuscript for publication.

\section{Author details}

'Department of Epidemiology, GROW - School for Oncology \& Developmental Biology, Maastricht University, P.O. Box 616, Maastricht 6200 MD, The Netherlands. ${ }^{2}$ Department of Otorhinolaryngology, Head \& Neck Surgery, GROW - School for Oncology \& Developmental Biology, Maastricht University Medical Center, Maastricht, The Netherlands. ${ }^{3}$ TNO, Leiden, The Netherlands.

Received: 11 October 2013 Accepted: 27 February 2014

Published: 14 March 2014

\section{References}

1. Argiris A, Karamouzis MV, Raben D, Ferris RL: Head and neck cancer. Lancet 2008, 371(9625):1695-1709.

2. Ferlay J, Shin HR, Bray F, Forman D, Mathers C: D.M. P: GLOBOCAN 2008 v1.2, Cancer Incidence and Mortality Worldwide: IARC CancerBase No. 10 [Internet]. Lyon, France: International Agency for Research on Cancer; 2010. Available from: http://globocan.iarc.fr, accessed on 30/05/2013.

3. World Cancer Research Fund: American Institute for Cancer Research: Food, Nutrition, Physical Activity and the Prevention of Cancer: a Global Perspective. Washington DC: American Institute for Cancer Research; 2007.

4. IARC: Monographs on the evaluation of carcinogenic risks to humans: alcohol drinking. Lyon: International Agency for Research on Cancer; 1988.

5. IARC: Monographs on the evaluation of carcinogenic risks to humans: tobacco smoke and involuntary smoking. Lyon: International Agency for Research on Cancer; 2004

6. Bagnardi V, Blangiardo M, La Vecchia C, Corrao G: Alcohol consumption and the risk of cancer: a meta-analysis. Alcohol Res Health 2001, 25(4):263-270

7. Gandini S, Botteri E, lodice S, Boniol M, Lowenfels AB, Maisonneuve P, Boyle P: Tobacco smoking and cancer: a meta-analysis. Int J Cancer 2008, 122(1):155-164.

8. Lubin JH, Purdue M, Kelsey K, Zhang ZF, Winn D, Wei Q, Talamini R, Szeszenia-Dabrowska N, Sturgis EM, Smith E, Shangina O, Schwartz SM, Rudnai P, Neto JE, Muscat J, Morgenstern H, Menezes A, Matos E, Mates IN, Lissowska J, Levi F, Lazarus P, La Vecchia C, Koifman S, Herrero R, Franceschi S, Wünsch-Filho V, Fernandez L, Fabianova E, Daudt AW, et al: Total exposure and exposure rate effects for alcohol and smoking and risk of head and neck cancer: a pooled analysis of case-control studies. Am J Epidemiol 2009, 170(8):937-947.

9. Boeing $\mathrm{H}$ : Alcohol and risk of cancer of the upper gastrointestinal tract: first analysis of the EPIC data. IARC SCi Publ 2002, 156:151-154.

10. Freedman ND, Abnet CC, Leitzmann MF, Hollenbeck AR, Schatzkin A Prospective investigation of the cigarette smoking-head and neck cancer association by sex. Cancer 2007, 110(7):1593-1601.

11. Freedman ND, Schatzkin A, Leitzmann MF, Hollenbeck AR, Abnet CC: Alcohol and head and neck cancer risk in a prospective study. $\mathrm{Br} J$ Cancer 2007, 96(9):1469-1474.

12. Gronbaek M, Becker U, Johansen D, Tonnesen H, Jensen G, Sorensen TI: Population based cohort study of the association between alcohol intake and cancer of the upper digestive tract. BMJ 1998, 317(7162):844-847.

13. Kato I, Nomura AM, Stemmermann GN, Chyou PH: Prospective study of the association of alcohol with cancer of the upper aerodigestive tract and other sites. Cancer Causes Control 1992, 3(2):145-151.

14. Kjaerheim K, Gaard M, Andersen A: The role of alcohol, tobacco, and dietary factors in upper aerogastric tract cancers: a prospective study of 10,900 Norwegian men. Cancer Causes Control 1998, 9(1):99-108.
15. Zheng W, Sellers TA, Doyle TJ, Kushi LH, Potter JD, Folsom AR: Retinol, antioxidant vitamins, and cancers of the upper digestive tract in a prospective cohort study of postmenopausal women. Am J Epidemiol 1995, 142(9):955-960.

16. Hashibe M, Brennan P, Chuang SC, Boccia S, Castellsague X, Chen C, Curado MP, Dal Maso L, Daudt AW, Fabianova E, Fernandez L, Wünsch-Filho V, Franceschi S, Hayes RB, Herrero R, Kelsey K, Koifman S, La Vecchia C, Lazarus $P$, Levi F, Lence JJ, Mates D, Matos E, Menezes A, McClean MD, Muscat J, Eluf-Neto J, Olshan AF, Purdue M, Rudnai P, et al: Interaction between tobacco and alcohol use and the risk of head and neck cancer: pooled analysis in the International Head and Neck Cancer Epidemiology Consortium. Cancer Epidemiol Biomarkers Prev 2009, 18(2):541-550.

17. Goldstein BY, Chang SC, Hashibe M, La Vecchia C, Zhang ZF: Alcohol consumption and cancers of the oral cavity and pharynx from 1988 to 2009: an update. Eur J Cancer Prev 2010, 19(6):431-465.

18. IARC: Monographs on the evaluation of carcinogenic risks to humans: personal habits and indoor combustions. Lyon: International Agency for Research on Cancer; 2012.

19. van den Brandt PA, Goldbohm RA, Van 't Veer P, Volovics A, Hermus RJ, Sturmans F: A large-scale prospective cohort study on diet and cancer in The Netherlands. J Clin Epidemiol 1990, 43(3):285-295.

20. Barlow WE, Ichikawa L, Rosner D, Izumi S: Analysis of case-cohort designs. J Clin Epidemiol 1999, 52(12):1165-1172.

21. van den Brandt PA, Schouten LJ, Goldbohm RA, Dorant E, Hunen PM: Development of a record linkage protocol for use in the Dutch Cancer Registry for Epidemiological Research. Int J Epidemiol 1990, 19(3):553-558.

22. Goldbohm RA, Van den Brandt PA, Dorant E: Estimation of the coverage of Dutch municipalities by cancer registries and PALGA based on hospital discharge data. Tijdschr Soc Gezondheidsz 1994, 72:80-84.

23. Hashibe M, Brennan P, Benhamou S, Castellsague X, Chen C, Curado MP, Dal Maso L, Daudt AW, Fabianova E, Fernandez L, Wünsch-Filho V, Franceschi S, Hayes RB, Herrero R, Koifman S, La Vecchia C, Lazarus P, Levi F, Mates D, Matos E, Menezes A, Muscat J, Eluf-Neto J, Olshan AF, Rudnai P, Schwartz SM, Smith E, Sturgis EM, Szeszenia-Dabrowska N, Talamini R, et al: Alcohol drinking in never users of tobacco, cigarette smoking in never drinkers, and the risk of head and neck cancer: pooled analysis in the International Head and Neck Cancer Epidemiology Consortium. J Natl Cancer Inst 2007, 99(10):777-789.

24. Fritz AG: International Classification of Diseases for Oncology: ICD-O. 3rd edition. Geneva: World Health Organization; 2000.

25. NEVO table: Dutch food composition table, 1986-1987. In The Haque. the Netherlands: Voorlichtingbureau Voor de Voeding; 1986.

26. Brants HAM, Den Breeijen $\mathrm{H}$ : Beschrijving en verantwoording van de codering van NEVO-codes, standaardporties e.d. (Description of and justification for coding of the NEVO-codes, standardized serving sizes, etc. [in Dutch]). Zeist, the Netherlands: Institution CIVO - Toxicology and Nutrition TNO; 1990.

27. Bongaerts BW, van den Brandt PA, Goldbohm RA, De Goeij AF, Weijenberg MP: Alcohol consumption, type of alcoholic beverage and risk of colorectal cancer at specific subsites. Int I Cancer 2008, 123(10):2411-2417.

28. Goldbohm RA, van den Brandt PA, Brants HA, van't Veer P, Al M, Sturmans F, Hermus RJ: Validation of a dietary questionnaire used in a large-scale prospective cohort study on diet and cancer. Eur I Clin Nutr 1994, 48(4):253-265

29. Goldbohm RA, Van 't Veer P, Van Den Brandt PA, Van 't Hof MA, Brants HA, Sturmans F, Hermus RJ: Reproducibility of a food frequency questionnaire and stability of dietary habits determined from five annually repeated measurements. Eur J Clin Nutr 1995, 49(6):420-429.

30. Negri E, Boffetta P, Berthiller J, Castellsague X, Curado MP, Dal Maso L, Daudt AW, Fabianova E, Fernandez L, Wunsch-Filho V, Franceschi S, Hayes RB, Herrero R, Koifman S, Lazarus P, Lence JJ, Levi F, Mates D, Matos E, Menezes A, Muscat J, Eluf-Neto J, Olshan AF, Rudnai P, Shangina O, Sturgis EM, Szeszenia-Dabrowska N, Talamini R, Wei Q, Winn DM, et al: Family history of cancer: pooled analysis in the International Head and Neck Cancer Epidemiology Consortium. Int J Cancer 2009, 124(2):394-401.

31. Galeone C, Tavani A, Pelucchi C, Turati F, Winn DM, Levi F, Yu GP, Morgenstern H, Kelsey K, Dal Maso L, Purdue MP, McClean M, Talamini R, Hayes RB, Franceschi S, Schantz S, Zhang ZF, Ferro G, Chuang SC, Boffetta P, La Vecchia C, Hashibe M: Coffee and tea intake and risk of head and neck cancer: pooled analysis in the international head and neck cancer epidemiology consortium. Cancer Epidemiol Biomarkers Prev 2010, 19(7):1723-1736. 
32. Barlow WE: Robust variance estimation for the case-cohort design. Biometrics 1994, 50(4):1064-1072.

33. Schoenfeld D: Partial residuals for the proportional hazards regression model. Biometrika 1982, 69(1):239-241.

34. Leffondre K, Abrahamowicz M, Siemiatycki J, Rachet B: Modeling smoking history: a comparison of different approaches. Am J Epidemiol 2002, 156(9):813-823.

35. Wacholder S, Gail MH, Pee D, Brookmeyer R: Alternative Variance and Efficiency Calculations for the Case-Cohort Design. Biometrika 1989, 76(1):117-123.

36. De Vogel S, Dindore V, Van Engeland M, Goldbohm RA, van den Brandt PA, Weijenberg MP: Dietary folate, methionine, riboflavin, and vitamin B-6 and risk of sporadic colorectal cancer. J Nutr 2008, 138(12):2372-2378.

37. Pelucchi C, Gallus S, Garavello W, Bosetti C, La Vecchia C: Alcohol and tobacco use, and cancer risk for upper aerodigestive tract and liver. Eur J Cancer Prev 2008, 17(4):340-344.

38. Chyou PH, Nomura AM, Stemmermann GN: Diet, alcohol, smoking and cancer of the upper aerodigestive tract: a prospective study among Hawaii Japanese men. Int J Cancer 1995, 60(5):616-621.

39. Boffetta P, Hashibe M: Alcohol and cancer. Lancet Oncol 2006, 7(2):149-156.

40. Bagnardi V, Blangiardo M, La Vecchia C, Corrao G: A meta-analysis of alcohol drinking and cancer risk. Br J Cancer 2001, 85(11):1700-1705.

41. Zeka A, Gore R, Kriebel D: Effects of alcohol and tobacco on aerodigestive cancer risks: a meta-regression analysis. Cancer Causes Control 2003, 14(9):897-906.

42. Purdue MP, Hashibe M, Berthiller J, La Vecchia C, Dal Maso L, Herrero R, Franceschi S, Castellsague X, Wei Q, Sturgis EM, Morgenstern H, Zhang ZF, Levi F, Talamini R, Smith E, Muscat J, Lazarus P, Schwartz SM, Chen C, Neto JE, Wünsch-Filho V, Zaridze D, Koifman S, Curado MP, Benhamou S, Matos E, Szeszenia-Dabrowska N, Olshan AF, Lence J, Menezes A, et al: Type of alcoholic beverage and risk of head and neck cancer-a pooled analysis within the INHANCE Consortium. Am J Epidemiol 2009, 169(2):132-142.

43. Balder HF, Goldbohm RA, van den Brandt PA: Dietary patterns associated with male lung cancer risk in the Netherlands Cohort Study. Cancer Epidemiol Biomarkers Prev 2005, 14(2):483-490.

44. Marron M, Boffetta P, Zhang ZF, Zaridze D, Wunsch-Filho V, Winn DM, Wei Q, Talamini R, Szeszenia-Dabrowska N, Sturgis EM, Smith E, Schwartz SM, Rudnai P, Purdue MP, Olshan AF, Eluf-Neto J, Muscat J, Morgenstern H, Menezes A, McClean M, Matos E, Mates IN, Lissowska J, Levi F, Lazarus P, La Vecchia C, Koifman S, Kelsey K, Herrero R, Hayes RB, et al: Cessation of alcohol drinking, tobacco smoking and the reversal of head and neck cancer risk. Int J Epidemiol 2010, 39(1):182-196.

45. D'Souza G, Kreimer AR, Viscidi R, Pawlita M, Fakhry C, Koch WM, Westra WH, Gillison ML: Case-control study of human papillomavirus and oropharyngeal cancer. N Engl J Med 2007, 356(19):1944-1956.

46. Hobbs CG, Sterne JA, Bailey M, Heyderman RS, Birchall MA, Thomas SJ: Human papillomavirus and head and neck cancer: a systematic review and meta-analysis. Clin Otolaryngol 2006, 31(4):259-266.

47. Curado MP, Hashibe M: Recent changes in the epidemiology of head and neck cancer. Curr Opin Oncol 2009, 21(3):194-200.

48. Marur S, Forastiere AA: Head and neck cancer: changing epidemiology, diagnosis, and treatment. Mayo Clin Proc 2008, 83(4):489-501.

49. Mehanna H, Beech T, Nicholson T, El-Hariry I, McConkey C, Paleri V, Roberts $S$ : Prevalence of human papillomavirus in oropharyngeal and nonoropharyngeal head and neck cancer-systematic review and metaanalysis of trends by time and region. Head Neck 2012, 35(5):747-755.

50. Dobrossy L: Epidemiology of head and neck cancer: magnitude of the problem. Cancer Metastasis Rev 2005, 24(1):9-17.

\section{Submit your next manuscript to BioMed Central and take full advantage of:}

- Convenient online submission

- Thorough peer review

- No space constraints or color figure charges

- Immediate publication on acceptance

- Inclusion in PubMed, CAS, Scopus and Google Scholar

- Research which is freely available for redistribution

Submit your manuscript at www.biomedcentral.com/submit
Ciomed Central 